\title{
Erinnerungskultur in Vietnam
}

\author{
Thu-Trang Vuong \\ Sciences Po Paris \\ 27 Rue Saint-Guillaume, 75007 Paris, France \\ Email: thutrang.vuong@sciencespo.fr \\ Diese Entwurfsversion: v.1 \\ Versionsdatum: 8. Oktober 2019
}

Die neuzeitliche Geschichte von Vietnam wurde von Kolonialismus und Invasion markiert. Von der Ende des 19. Jahrhunderts war Vietnam eine französische Kolonie. Während des Zweiten Weltkriegs wurden die Vietnamesische Bevölkerung von drei Machte unterdrückt: von der Feudalherrschaft (die damals nur als Strohmann regelt und keine mehr Souveränität hatte), von den japanischen faschisten Truppen, und von der französischen kolonialen Verwaltung (die wegen der Vichy-Regime in Frankreich auch an den japanischen faschisten eine Annäherung machte). Obwohl die Vietnamesen selbst gegen der japanische Armee kämpften und 1945 die Unabhängigkeit erklärten, kehrten die Franzosen nach dem Zweiten Weltkrieg zu Vietnam zurück, französische Souveränität zu verlangen.

Dies führte zum Ersten Indochina-Krieg (1945-1954) zwischen Vietnam und Frankreich, nachdem Vietnam an zwei geteilt wurde: die kommunistische Demokratische Republik Vietnam im Norden und die Republik Vietnam im Süden. Wegen US-Intervention brach ein Krieg wieder aus. Nur nach der Befreiung von Saigon am 30.4.1975 wurde Vietnam wiedervereinigt und endlich (relativ) friedlich. (Eigentlich gab es noch Kriege gegen Khmer Rouge bis 1978 und dann gegen chinesische Angriffe in 1979. Aber diese Veranstaltungen werden nicht als "großen“ Kriege anerkannt...).

Darum war Nachkriegszeit Vietnams nicht die Jahre 1940s, sondern am Ende der 1970s. In Vietnam spricht man außer Geschichtsunterricht fast nicht über die Weltkriege. Unsere Kriegszeit ist der Französische Krieg und der Amerikanische Krieg. Manchmal diskutiert man die japanische Besetzung, aber nur als Zusammenhang von die unter der Vietminh August-Revolution, und das ist alle.

Gibt es dann eine Erinnerungskultur in Vietnam? Ja, wahrscheinlich. Aber nicht nur eine. Offizielle waren wir Opfer von Kolonialismus und Imperialismus und auch Held dagegen. Unsere sogenannte "offizielle“ Erinnerungskultur ist aus nationalistischem Stolz. Bei Vietnamesen ist Nationalismus keine rechtsstehende Ideologie, weil wir kein pluralistisches Parteiensystem haben. Außerdem hängt Nationalismus historisch mit Befreiung von Feudalgesellschaft und von Kolonialmächte, mit Widerstand gegen Angreifer und mit der Wiedervereinigung zusammen. Und es ist nicht total falsch; die vietnamesische Bevölkerung haben für ihre Recht und Freiheit gekämpft und wir können das anerkennen und auf das stolz sein.

Trotzdem gibt es andere Teilen von Geschichte, an der nicht alle Vietnamesen erinnert sich. Das Datum 30.4 wird nur von die Nördliche als „Befreiung“ genannt. Es ist der Fall von Saigon - eine Niederlage gegen die Kommunisten - für viele südliche Leute, für viele Bürger vom Republik Vietnam, für viele "Saigoner“ (Saigonese), die fliehen mussten. Die Zwangsmigration von Südvietnam wird oft auch als ein Exodus von „boatpeople“ bekannt. Die Mehrheit dieser Flüchtlinge endeten in der USA oder in Kanada; die andere, in Europa. Sie werden schließlich eingebürgert und haben vietnamesische Gemeinschaften gebildet. Sie sich erinnern an den „Amerikanische Krieg“ als ein Bürgerkrieg, in dem der Süd ist das Opfer und der kommunistische Norden ist der Usurpator. Heute sag man nicht mehr so, aber unterbewusst bleibt die Mentalität mehr oder weniger da, sowohl für Flüchtlinge als auch südliche Leute in Vietnam. 


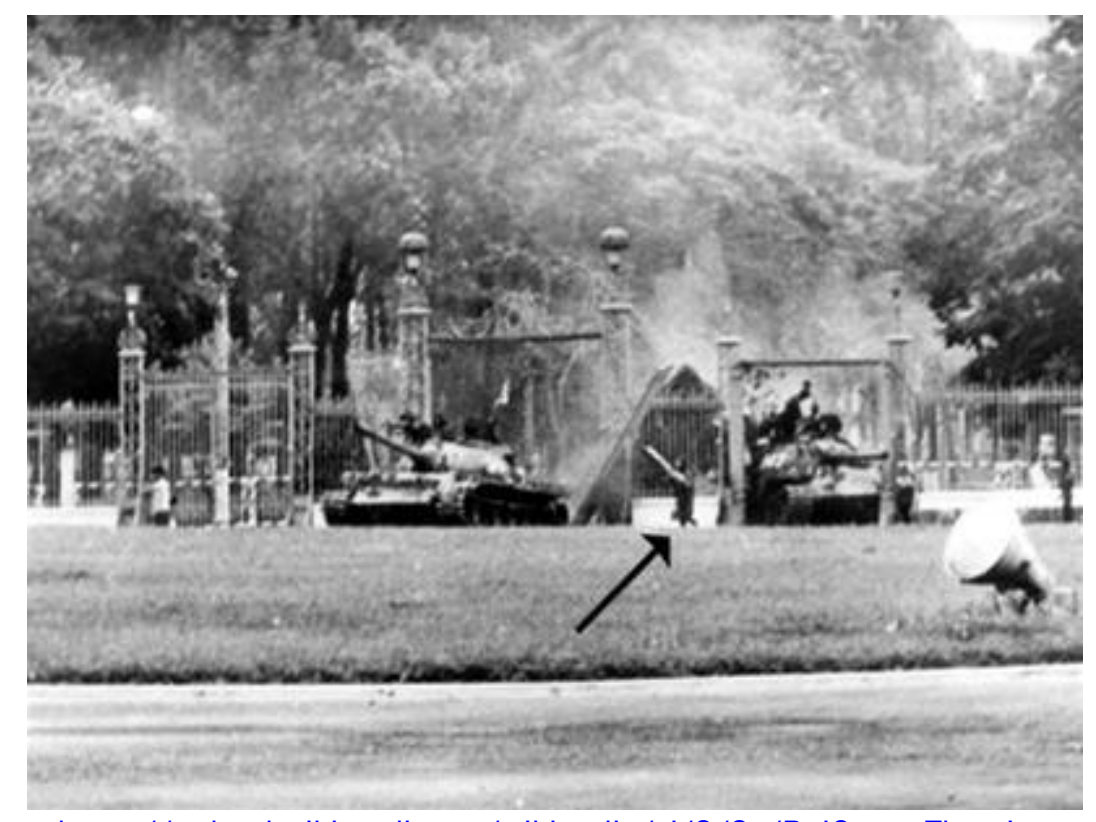

https://upload.wikimedia.org/wikipedia/vi/9/9c/BuiQuangThan.jpg

Eine andere Facett ist der Status von "Opfer“. Sind wir wirklich nur ein armer, unschuldiger Opfer? Tatsächlich war die vietnamesische Armee seit 10 Jahren Okkupanten in Kambodscha. Der Krieg zwischen die vietnamesischen Kommunisten und die Khmer Rouge, die auch als Südwestliche Grenzkrieg genannt wird, war zu kompliziert hinsichtlich des Motivation von beide Seite und die Beide waren Angreifer. Man kann aber nicht die vietnamesische Einmischung in kambodschanische Politik abstreiten. Dies ist ein Teil von Geschichte die fast nicht erinnert wird.

Zum Schluss frage ich mich, ob man eine Erinnerungskultur haben kann, wenn das Regime autoritär ist. Viele historische Tatsache bleiben lang versteckt hinter kommunistische Propaganda. Die Kommunistische Partei Vietnam regiert noch lange.

\section{Literaturverzeichnis}

Vuong, Q. H., Bui, Q. K., La, V. P., Vuong, T. T., Ho, T. M., Nguyen, H. K. T., Nguyen, N. H., Nghiem, P. K. C., \& Ho, M. T. (2019). Cultural evolution in Vietnam's early 20th century: a Bayesian networks analysis of Hanoi Franco-Chinese house designs. Social Sciences \& Humanities Open, 1(1), 100001; doi: 10.1016/j.ssaho.2019.100001.

Vuong, T. T., Semerák, V., \& Vuong, Q. H. (2019). The Vietnamese Economy at the Crossroads. In: Macdonald (Ed.). Southeast Asia and the ASEAN Economic Community (pp. 91-143). Cham, CH: Palgrave Macmillan. DOI: 10.1007/978-3-030-19722-3_3.

Vuong, T. T., \& Vuong, Q. H. (2018). L'Indochine française du XIXe-XXe siècle - politique et religions. Working Papers CEB, N¹8-002 (Université Libre de Bruxelles).

Vuong, Q.H., et al. (2018). “文化可加性”以及儒教, 佛教和道教的价值观和规范如何共存, 相互作用和影响越南社会:用R和Stan对于长期民间故事进行贝叶斯逻辑回归的分析. Philpapers ID VUOR (2018-04-20). Retrieved from: https://philarchive.org/rec/VUOR.

Vuong, Q. H., La, V. P., Ho, T. M., Nguyen, H. K. T., Vuong, T. T., Vu, T. H., Nguyen, M. H., \& Ho, M. T. (2019, September 26). On how religions could accidentally incite lies and violence: Folktales as a cultural transmitter. OSF Preprints, doi: 10.31219/osf.io/nb7tg. 